\title{
Ultrafast light-induced response of photoactive yellow protein chromophore analogues $\uparrow$
}

\author{
Agathe Espagne, $,_{+}^{a}, b$ Daniel H. Paik, $\oint^{b}$ Pascale Changenet-Barret, ${ }^{a}$ Pascal Plaza, ${ }^{a}$ Monique M. Martin ${ }^{* a}$ and \\ Ahmed H. Zewail $* b$
}

Received 22nd January 2007, Accepted 29th March 2007

First published as an Advance Article on the web 18th April 2007

DOI: $10.1039 / \mathrm{b} 700927 \mathrm{e}$

The fluorescence decays of several analogues of the photoactive yellow protein (PYP) chromophore in aqueous solution have been measured by femtosecond fluorescence up-conversion and the corresponding time-resolved fluorescence spectra have been reconstructed. The native chromophore of PYP is a thioester derivative of $p$-coumaric acid in its trans deprotonated form. Fluorescence kinetics are reported for a thioester phenyl analogue and for two analogues where the thioester group has been changed to amide and carboxylate groups. The kinetics are compared to those we previously reported for the analogues bearing ketone and ester groups. The fluorescence decays of the full series are found to lie in the 1-10 ps range depending on the electron-acceptor character of the substituent, in good agreement with the excited-state relaxation kinetics extracted from transient absorption measurements. Steady-state photolysis is also examined and found to depend strongly on the nature of the substituent. While it has been shown that the ultrafast light-induced response of the chromophore in PYP is controlled by the properties of the protein nanospace, the present results demonstrate that, in solution, the relaxation dynamics and pathway of the chromophore is controlled by its electron donor-acceptor structure: structures of stronger electron donor-acceptor character lead to faster decays and less photoisomerisation.

\section{Introduction}

A number of studies have been devoted to the characterisation of the earliest photochemical steps involved in the transduction of blue light by PYP (photoactive yellow protein): ${ }^{1-6}$ the photosensory receptor thought to trigger the photomotility of the flagellate bacterium Halorhodospira halophila. ${ }^{7}$ For PYP, like for other natural photoreceptors that have been characterised so far and are involved in a variety of biological functions, ${ }^{8}$ the fundamental question raised by physical chemists is: how are intrinsic photoinduced processes in an organic chromophore used and controlled within a macromolecule to trigger a chain of reactions leading to a precise function?

PYP is a small $(14 \mathrm{kDa})$ water-soluble protein, the photoactivity of which has been the subject of several reviews. ${ }^{1-5}$ Its chromophore is a thioester derivative of $p$-coumaric acid in its trans deprotonated form (see $\mathrm{pCA}^{2-}$, Scheme 1). Its structure is composed of a

${ }^{a}$ UMR CNRS-ENS 8640 P.A.S.T.E.U.R., Département de Chimie, Ecole Normale Supérieure, 24 rue Lhomond, 75005, Paris, France. E-mail: monique.martin@ens.fr; Fax: +331443233 25; Tel: +331 443224 12

${ }^{b}$ Laboratory for Molecular Sciences, Arthur Amos Noyes Laboratory of Chemical Physics, California Institute of Technology, Pasadena, California, 91125, USA. E-mail: zewail@caltech.edu; Fax: +1 626792 8456; Tel: +1 6263956536

$\dagger$ Electronic supplementary information (ESI) available: Steady-state absorption and fluorescence spectra of PYP chromophore analogues (Fig. S1). See DOI: $10.1039 / \mathrm{b} 700927 \mathrm{e}$

$\$$ Present address: Service de Bioénergétique, CEA-Saclay, 91191 Gif-surYvette Cedex, France.

$\S$ Present address: JILA, University of Colorado, 440 UCB, Boulder, CO 80309-0440, USA. phenolate group connected to a thioester group via a single ethylenic bond. It is covalently bound to the unique cystein residue of the protein (Cys69) through the thioester bond (see PYP, Scheme 1). The chromophore experiences steric constraints imposed by the geometry of the protein nanospace as well as hydrogen bonds with several amino acids (Glu46 and Tyr42 on the phenolate side and Cys69 on the carbonyl side) and an electrostatic interaction with an arginium cation (Arg52).

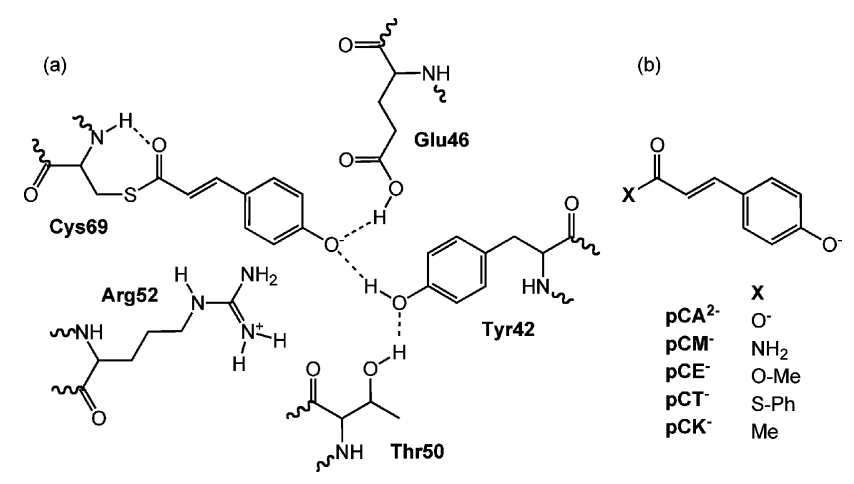

Scheme 1 A representation of the photoactive site of PYP (a) and the chemical structure of the PYP chromophore analogues studied in the present work (b).

The primary photochemistry of PYP was shown to rely on the trans-cis photoisomerisation of its chromophore which leads to successive chemical steps involving protein structural changes and chromophore protonation in a $c a$. $1 \mathrm{~s}$ full cycle. ${ }^{1,2}$ During this photocycle a signalling state is expected to be produced, which 
triggers the intracellular transduction chain up to the flagellae and thus the behavioural response of the bacterium.

Several anionic $p$-coumaric acid derivatives have already been studied in solution ${ }^{4,9-20}$ or in vacuo, ${ }^{21,22}$ by means of a variety of experimental methods. These studies emphasized the influence of the substituents ${ }^{4,12,15,16,18-20}$ and of the solvent polarity and viscosity ${ }^{18,19}$ on the relaxation pathway and relaxation dynamics. The influence of the carbonyl substituent (X, Scheme 1) on the excited-state lifetime was recently rationalised in terms of electron donor-acceptor structure of the analogue and the observed change in viscous damping was considered as an indication that the relaxation coordinate depends on the donor-acceptor structure. ${ }^{18,20}$ In a previous publication, ${ }^{19}$ we also highlighted the major influence of the protonation state of the phenolate group on the viscous damping of the excited-state decay of the ester ( $\mathrm{pCEH}$ versus $\mathrm{pCE}^{-} ; \mathrm{X}=\mathrm{O}-\mathrm{CH}_{3}$, Scheme 1 ) and ketone (pCKH versus $\mathrm{pCK}^{-} ; \mathrm{X}=\mathrm{CH}_{3}$ ) derivatives. We proposed that the very weak viscosity effect on the deactivation kinetics of protonated chromophores (pCEH and $\mathrm{pCKH}$ ) suggests concerted motions such as in the hula-twist or bicycle-pedal mechanisms. ${ }^{19}$

In the present study, we focus our attention on the fluorescence decays and time-resolved fluorescence spectra of the anionic derivatives bearing an amide $\left(\mathrm{pCM}^{-}, \mathrm{X}=\mathrm{NH}_{2}\right.$, Scheme 1), or a carboxylate $\left(\mathrm{pCA}^{2-}, \mathrm{X}=\mathrm{O}^{-}\right.$) group; the chromophore of PYP being modelled by the phenyl thioester derivative $\left(\mathrm{pCT}^{-}\right)$. The kinetics have been directly followed by femtosecond fluorescence upconversion and compared to those we previously reported for the analogues where the thioester group has been changed to a ketone $\left(\mathrm{pCK}^{-}\right)$and a methyl ester $\left(\mathrm{pCE}^{-}\right) .{ }^{19}$ The fluorescence decays are also compared to transient absorption kinetics previously reported by part of the present authors. ${ }^{9,10,12,20}$ We confirm the role of the electron donor-acceptor character of the chromophore structure on the observed kinetics and further discuss the intramolecular coordinates involved in the excited-state deactivation of these analogues in solution.

\section{Experimental}

\section{Samples}

Trans-p-hydroxycinnamic phenyl thioester (pCTH) and trans$p$-hydroxycinnamide ( $\mathrm{pCMH}$ ) were synthesized following the procedures described in ref. 10. Trans- $p$-hydroxycinnamic methyl ester $(\mathrm{pCEH})$ was synthesized as described in ref. 20. Transp-hydroxycinnamic acid $\left(\mathrm{pCAH}_{2}\right)$ was purchased from SigmaAldrich and trans- $p$-hydroxybenzylidene acetone $(\mathrm{pCKH})$ from Alfa Aesar. Aqueous and alcoholic solutions of $\mathrm{pCA}^{2-}, \mathrm{pCM}^{-}$and $\mathrm{pCK}^{-}$were prepared with $0.05 \mathrm{M} \mathrm{KOH}(\mathrm{pH}=12.7)$ to achieve complete deprotonation. In order to avoid solvolysis during the experiments, aqueous solutions of $\mathrm{pCE}^{-}$and $\mathrm{pCT}^{-}$were prepared in buffers at pH 10.2 (Britton-Robinson borate buffer) or 10.4 (CAPS). Alcoholic solutions of $\mathrm{pCE}^{-}$and $\mathrm{pCT}^{-}$contained $5 \times$ $10^{-4} \mathrm{M} \mathrm{KOH}$ in order to achieve $95 \%$ deprotonation and sufficient chemical stability. The optical density of the samples was adjusted to respectively 1 per $\mathrm{mm}$ and 0.1 per $\mathrm{cm}$ at the absorption maximum, for steady-state absorption and fluorescence measurements and to 1 per mm for time-resolved measurements. The stability of the samples during the time-resolved measurements was checked continuously by measuring their steady-state absorbance. Less than $5 \%$ degradation was observed.

Steady-state spectra were recorded with a double-beam UVvisible spectrometer SAFAS UVmc2) and a spectrofluorometer (Jobin Yvon Horiba, Fluoromax 3). Fluorescence spectra were corrected from the instrumental wavelength-dependent response. NMR spectra were recorded on a Brucker AM 250 instrument. For steady-state photolysis experiments, samples were continuously irradiated by a xenon lamp in the cell compartment of the fluorometer and evolution of the sample optical density was checked at regular time-intervals.

\section{Time-resolved spectroscopy}

The fluorescence up-conversion set-up has been described elsewhere. ${ }^{23}$ An amplified femtosecond Ti-sapphire laser was used as the excitation source. The output of the regenerative amplifier $(120 \mathrm{fs}, 800 \mathrm{~nm}, 1 \mathrm{kHz})$ was split into two beams of equal intensity. One beam was used to pump an optical parametric amplifier in order to generate infrared pulses at $1360 \mathrm{~nm}$, which were then frequency-doubled twice. The $340 \mathrm{~nm}$ output pulses were used to excite the sample ( $c$. $200 \mathrm{~nJ}$ pulse ${ }^{-1}$ focussed on a $0.3 \mathrm{~mm}$ diameter spot). The remaining $800 \mathrm{~nm}$ beam was used as the gate. The sample was held in a $0.6 \mathrm{~mm}$ path-length rotating cell. The fluorescence emitted by the sample was collected by a set of two parabolic mirrors and spatially overlapped with the $800 \mathrm{~nm}$ gate pulses in a $0.9 \mathrm{~mm}$ thick $\mathrm{BBO}$ crystal to produce the upconverted signal by sum-frequency generation. The spectral region corresponding to the very blue edge of the fluorescence spectrum, which overlaps with the absorption spectrum, was not considered in this work. The pump polarization was set to the magic angle $\left(54.7^{\circ}\right)$ with respect to the gate polarization. The fluorescence decays were obtained by varying the time delay between the pump and gate pulses. The time-resolution of the set-up was estimated to be about $500 \mathrm{fs}$ from the fits according to the procedure described in ref. 23. To reconstruct the time-resolved spectra, we followed the procedure described in ref. 24: the spectrum at a given time delay was obtained from the fitted kinetics series by normalization of the integrated signals at the different wavelengths with respect to the steady-state fluorescence spectrum. The spectra were fitted to a lognormal shape to determine their maximum wavenumber, $\bar{v}(t)$. The normalized shift of the emission band with time, $C(t)$, was defined as $C(t)=\frac{\bar{v}(t)-\bar{v}(\infty)}{\bar{v}(0)-\bar{v}(\infty)} \bar{v}(0)$ and $\bar{v}(\infty)$ were obtained from an exponential fit of $\bar{v}(t)$.

\section{Results and discussion}

\section{Steady-state absorption and fluorescence spectra}

The normalised absorption and fluorescence spectra of the full series of analogues in basic aqueous solution are given in the ESI, Fig. S1. $\dagger$ There is a progressive redshift of both spectra, i.e. of the lowest $\pi-\pi^{*}$ transition, when the substituted carbonyl end group is changed from a carboxylate $\left(\mathrm{pCA}^{2-}\right)$ to an amide $\left(\mathrm{pCM}^{-}\right)$, an ester $\left(\mathrm{pCE}^{-}\right)$, a ketone $\left(\mathrm{pCK}^{-}\right)$and a thioester $\left(\mathrm{pCT}^{-}\right)$. The redshift of the absorption spectra can also be seen in Fig. 2 (see later). As emphasized in a previous comparison of $\mathrm{pCA}^{2-}, \mathrm{pCM}^{-}$ and $\mathrm{pCT}^{-},{ }^{18}$ the observed redshift correlates with the progressive increase of the electron acceptor strength of the carbonyl tail (X, 
Scheme 1). The amplitude of the fluorescence redshift is smaller than that of the absorption, which leads to a progressive decrease of the large fluorescence Stokes shift from $6800 \mathrm{~cm}^{-1}$ for $\mathrm{pCA}^{2-}$ to $5200 \mathrm{~cm}^{-1}$ for $\mathrm{pCT}^{-}$. From a detailed study of the solvent-induced shift of the absorption and fluorescence spectra of $\mathrm{pCA}^{2-}, \mathrm{pCM}^{-}$ and $\mathrm{pCT}^{-18}$ in protic and aprotic solvents, it was shown that the hydrogen-bond interaction between the phenolate group and the solvent is strongly weakened upon excitation, partly explaining the large Stokes shift. In all cases, the absorption spectrum is broader than the fluorescence spectrum. Considering that the lower band is due to a single electronic transition, ${ }^{18}$ it is an indication that the excited-state surface is steeper than that of the ground state around the equilibrium geometry of the ground state. The absorption above $32000 \mathrm{~cm}^{-1}$ was shown to be due to a different electronic transition by fluorescence anisotropy measurements carried out on $\mathrm{pCA}^{2-}, \mathrm{pCM}^{-}$and $\mathrm{pCT}^{-18}$ and possibly corresponds to an $\mathrm{n} \pi^{*}$ transition located on the carbonyl end group. ${ }^{25}$ On the other hand the charge-transfer character of the emitting state ${ }^{18}$ was emphasised by the reported solvent polarity induced redshift of the fluorescence band, which will be further discussed in the section devoted to time-resolved measurements.

\section{Steady-state photolysis}

The analogues studied here are weakly fluorescent: in aqueous solutions their quantum yields of fluorescence have been estimated to be on the order of $0.1 \%{ }^{4,19}$ It was previously shown ${ }^{9,12}$ that, in basic aqueous solution, irradiation of $\mathrm{pCA}^{2-}$ and $\mathrm{pCM}^{-}$in the rededge of their absorption band leads to the formation of a stable cis isomer absorbing in the blue edge of the initial trans conformation. The presence of a cis isomer in a photolysed solution was already known for $\mathrm{pCA}^{2-}{ }^{26}$ For $\mathrm{pCM}^{-}$, it has been characterized by ${ }^{1} \mathrm{H}$ NMR. The spectrum displayed in Fig. 1 indeed shows shielding of the signals of the vinylic protons: the doublet at $\approx 5.71 \mathrm{ppm}$ and $6.55 \mathrm{ppm}$ is due to the $c i s$ isomer $\left({ }^{3} \mathrm{~J}=12.5 \mathrm{~Hz}\right)$ while that at $\approx 6.33 \mathrm{ppm}$ and $6.60 \mathrm{ppm}$ arises from the trans isomer $\left({ }^{3} J=\right.$ $15.7 \mathrm{~Hz}$ ).

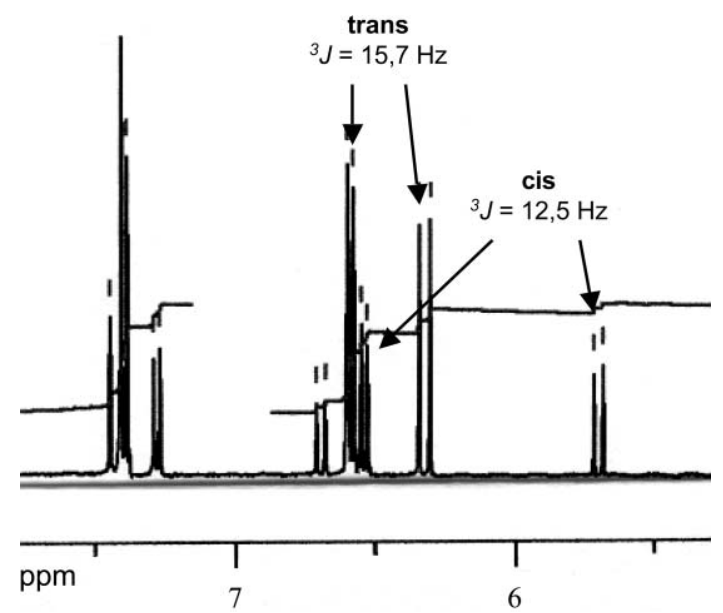

Fig. $1{ }^{1} \mathrm{H}$ NMR spectrum of a photolysed solution of $\mathrm{pCM}^{-}$, the amide derivative of deprotonated $p$-coumaric acid, in $\mathrm{D}_{2} \mathrm{O}$ containing $5 \times 10^{-2} \mathrm{M}$ KOD. The doublet at $\approx 5.71 \mathrm{ppm}$ and $6.55 \mathrm{ppm}$ is due to the cis isomer $\left({ }^{3} J=12.5 \mathrm{~Hz}\right)$ while that at $\approx 6.33 \mathrm{ppm}$ and $6.60 \mathrm{ppm}$ arises from the trans isomer $\left({ }^{3} J=15.7 \mathrm{~Hz}\right)$.
In Fig. 2, we have compared the evolution of the UV-visible absorption spectra of $\mathrm{pCA}^{2-}, \mathrm{pCM}^{-}, \mathrm{pCE}^{-}$and $\mathrm{pCK}^{-}$in basic solution of methanol under steady-state irradiation. Note that solvolysis of $\mathrm{pCE}^{-}$does not lead to any net change in the chemical structure in this solvent. Fig. 2 also shows the photolysis of $\mathrm{pCT}^{-}$in CAPS buffer solution at $\mathrm{pH}$ 10.4; conditions which were chosen to avoid hydrolysis during irradiation. Although these measurements do not allow to quantify the photoisomerisation yield of the different analogues, they provide information on whether a stable photoproduct is formed or not. The figure shows the spectral change due to the $c i s$-isomer formation of $\mathrm{pCA}^{2-}$ and $\mathrm{pCM}^{-}$. One also notes a similar but much smaller spectral change for $\mathrm{pCE}^{-}$: the band slightly decreases around its maximum, while an isosbestic point appears on its blue side. This evolution can be attributed to the $c i$ isomer by comparison with $\mathrm{pCA}^{2-}$ and $\mathrm{pCM}^{-}$. On the contrary, irradiation of $\mathrm{pCK}^{-}$and $\mathrm{pCT}^{-}$does not lead to any change of the absorption spectrum, indicating that no stable photoproduct is formed and thus that the photoisomerisation yield of those two analogues is likely negligible. Photoinduced relaxation mechanisms leading either to the cis isomer or mainly

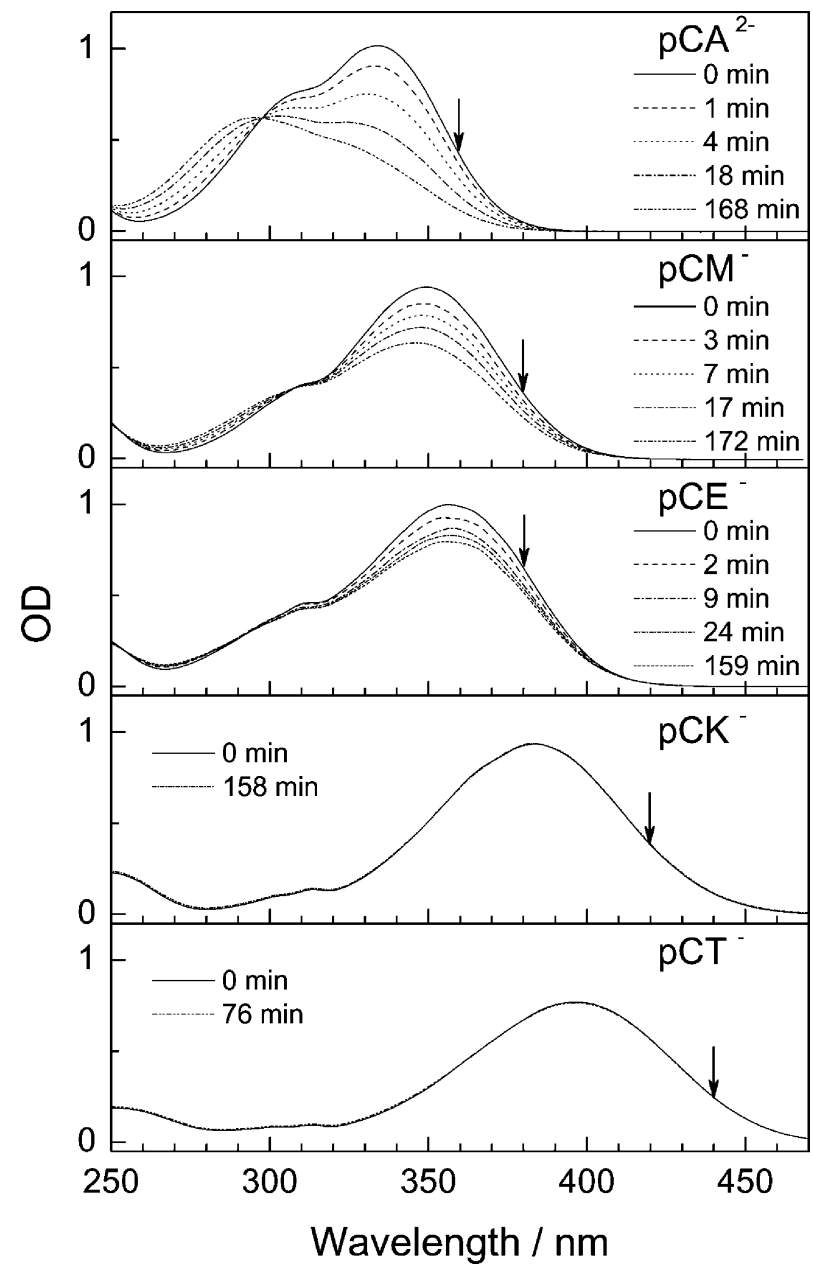

Fig. 2 Evolution of the ground-state absorption of the deprotonated PYP chromophore analogues of the chromophore presented in Scheme 1, upon steady-state irradiation. Irradiation of $\mathrm{pCA}^{2-}$ at $360 \mathrm{~nm}, \mathrm{pCM}^{-}$and $\mathrm{pCE}^{-}$ at $380 \mathrm{~nm}$ and $\mathrm{pCK}^{-}$at $420 \mathrm{~nm}$, has been carried out in basic solutions of methanol. The aqueous solution of $\mathrm{pCT}^{-}$in CAPS buffer at $\mathrm{pH} 10.4$ has been irradiated at $440 \mathrm{~nm}$. 
back to the initial trans form depending on the electron-donor acceptor character have been proposed by part of us for derivatives of $p$-hydroxycinnamic acid $^{18,20}$ and are further confirmed here. Variation of the photoisomerisation yield related to the electron donor-acceptor character of the chemical structure has already been reported, for example, for substituted pyrenyl-styrenes. ${ }^{27}$ The effect of the substitution site on the photoisomerisation yield of cinnamide derivatives has also been observed ${ }^{28}$ Recent reports stress both the effects of the substitution site ${ }^{29}$ and of the protonation state ${ }^{30}$ on the isomer ratio in photolysed solutions of coumaric amide derivatives.

\section{Time-resolved fluorescence spectra}

The time-resolved fluorescence spectra of $\mathrm{pCA}^{2-}, \mathrm{pCM}^{-}$, and $\mathrm{pCT}^{-}$in aqueous solutions are displayed in Fig. 3 (left). They were reconstructed from measurements of single-wavelength fluorescence decays across the spectra (every $10 \mathrm{~nm}$ ), which will be discussed in the next section. The reconstructed spectra of $\mathrm{pCK}^{-}$ and $\mathrm{pCE}^{-}$were previously reported in ref. 19. In all cases, the time-resolved fluorescence spectra exhibit both a redshift and a decay. The time-resolved shifts represented by the normalized $C(t)$ curves are shown in Fig. 3 (right). They exhibit single or double-exponential decays with the following time components: $0.4 \mathrm{ps}(85 \%)$ and $1.5 \mathrm{ps}(15 \%)$ for $\mathrm{pCA}^{2-} ; 0.8 \mathrm{ps}$ for $\mathrm{pCM}^{-}$; $0.9 \mathrm{ps}$ for $\mathrm{pCT}^{-}$. For $\mathrm{pCE}^{-}$and $\mathrm{pCK}^{-}$the time constants were respectively 0.9 ps and 0.6 ps. $^{19}$ In all cases, the time-resolved shift occurs in the subpicosecond regime and is attributed to solvation dynamics. A value of 0.9 ps has indeed been reported for the longest component of solvation dynamics in water. ${ }^{31}$ Timeresolved shifts of the stimulated emission band found in transient absorption experiments of these compounds in different solvents had also been interpreted in terms of solvation effects. ${ }^{4,10,12,18,20}$ These effects are in agreement, on the one hand, with a reported large charge redistribution occurring upon optical excitation ${ }^{32}$ and, on the other hand, with the fluorescence spectra shifting to the red in solvents of increasing polarity. ${ }^{18}$

\section{Excited-state decay kinetics}

Typical fluorescence decays observed for $\mathrm{pCA}^{2-}, \mathrm{pCM}^{-}$, and $\mathrm{pCT}^{-}$at selected wavelengths are shown in Fig. 4. They were fitted to a sum of two exponential components convoluted with a Gaussian function describing the instrument response function. ${ }^{23}$ The fitting parameters are provided in Table 1 . Those previously

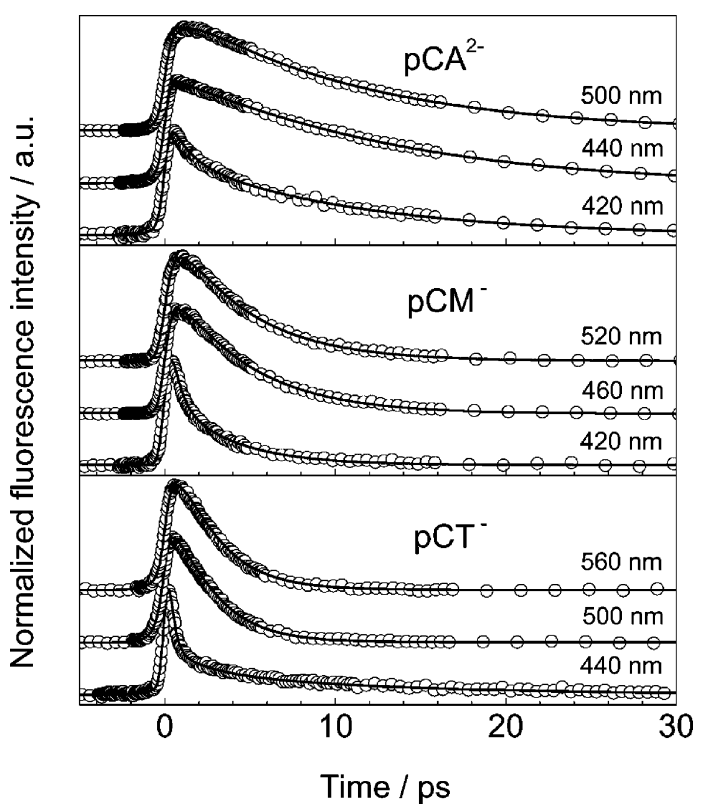

Fig. 4 Fluorescence decays of the deprotonated forms of trans-pcoumaric acid $\left(\mathrm{pCA}^{2-}\right)$, its amide derivative $\left(\mathrm{pCM}^{-}\right)$and its thioesterphenyl derivative $\left(\mathrm{pCT}^{-}\right)$in basic aqueous solutions, at selected wavelengths.
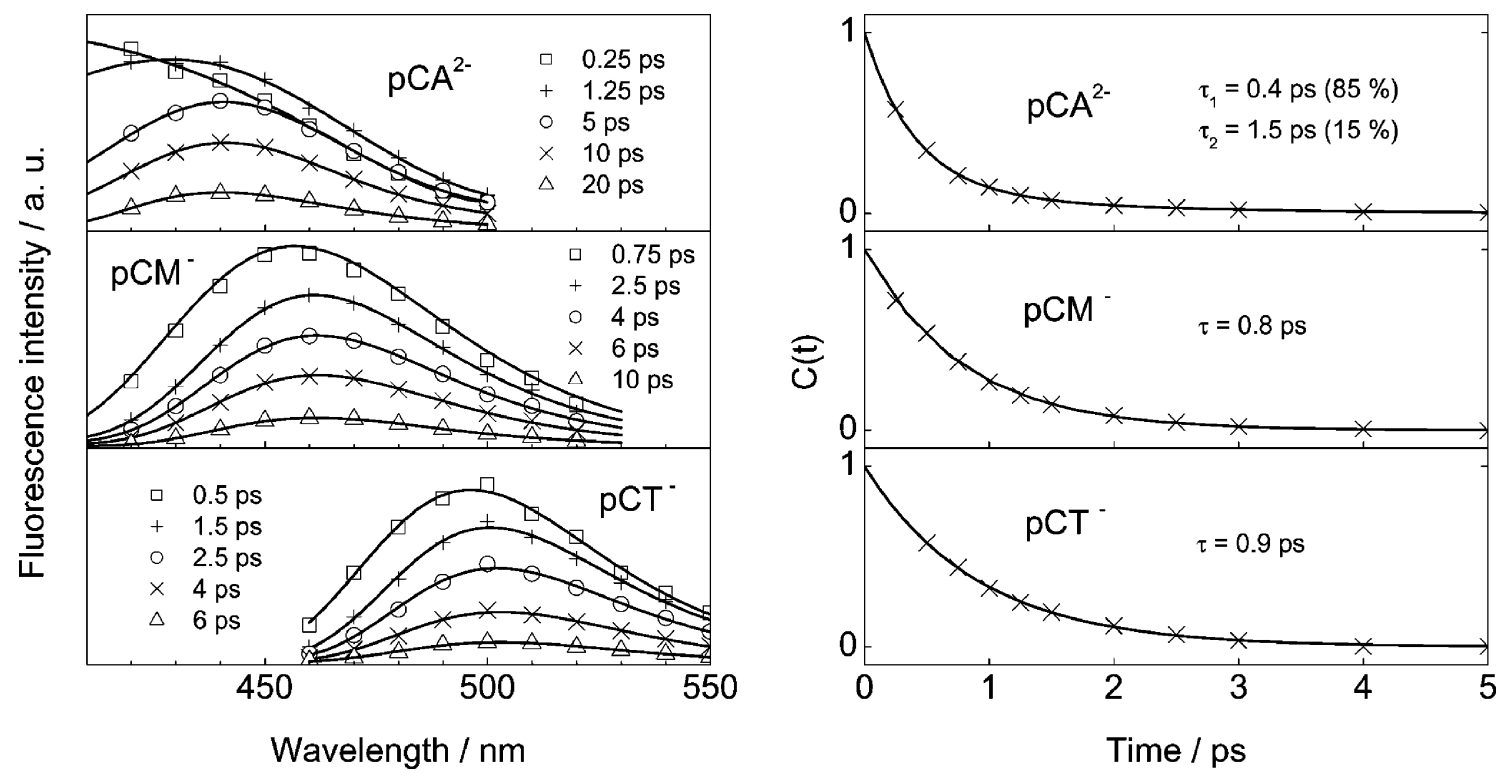

Fig. 3 Left: time-resolved fluorescence spectra of the deprotonated forms of trans-p-coumaric acid $\left(\mathrm{pCA}^{2-}\right)$, its amide derivative (pCM $\left.{ }^{-}\right)$and its thioester-phenyl derivative $\left(\mathrm{pCT}^{-}\right)$in basic aqueous solutions, reconstructed from single-wavelength decays measured by femtosecond fluorescence up-conversion. Right: normalised curves $C(t)$ describing the dynamic solvation-induced redshift of the fluorescence spectra of the three analogues. 
Table 1 Parameters used to fit the time-resolved fluorescence signals of basic aqueous solutions of all PYP chromophore analogues shown in Scheme 1, with a sum of two exponential components (preexponential factor $a_{i}$ and time-component $\tau_{i}$ ) convoluted with the response function of the fluorescence up-conversion set-up. Data for $\mathrm{pCE}^{-}$and $\mathrm{pCK}^{-}$are from ref. 19

\begin{tabular}{lllrrl}
\hline & $\lambda / \mathrm{nm}$ & $\tau_{1} / \mathrm{ps}$ & \multicolumn{1}{c}{$a_{1}$} & $\tau_{2} / \mathrm{ps}$ & \multicolumn{1}{l}{$a_{2}$} \\
\hline $\mathrm{pCA}^{2-}$ & 420 & 1.2 & 0.37 & 10.8 & 0.63 \\
& 460 & 1.4 & -0.21 & 12.1 & 0.79 \\
& 500 & 0.9 & -0.26 & 10.7 & 0.74 \\
$\mathrm{pCM}^{-}$ & 420 & 0.5 & 0.59 & 3.6 & 0.41 \\
& 460 & 0.7 & -0.25 & 4.5 & 0.75 \\
& 520 & 0.7 & -0.29 & 4.4 & 0.71 \\
$\mathrm{pCE}^{-}$ & 430 & 0.7 & 0.50 & 2.6 & 0.50 \\
& 460 & 1.1 & -0.29 & 3.0 & 0.71 \\
$\mathrm{pCT}^{-}$ & 490 & 0.8 & -0.31 & 2.8 & 0.69 \\
& 440 & 0.3 & 0.88 & 2.0 & 0.12 \\
$\mathrm{pCK}^{-}$ & 500 & 1.0 & -0.31 & 2.2 & 0.69 \\
& 460 & 0.8 & -0.35 & 2.3 & 0.65 \\
& 480 & 0.6 & 0.49 & 1.3 & 0.51 \\
& 500 & 0.2 & -0.27 & 1.3 & 0.73 \\
& 0.5 & -0.32 & 1.3 & 0.68 \\
\hline
\end{tabular}

reported for $\mathrm{pCK}^{-}$and $\mathrm{pCE}^{-19}$ are also given for comparison. The solvation-induced spectral shifts analysed in the previous section are characterised by wavelength-dependent subpicosecond component $\left(\tau_{1}\right)$ with a positive amplitude (decay) on the blue side of the emission band and a negative amplitude (rise) on the red side. The longest component $\left(\tau_{2}\right)$ is attributed to excited-state population decay. It is independent of the detection wavelength within experimental error and has a positive amplitude. Table 1 shows that the excited-state lifetime increases - in the 1-10 ps time range - if the carbonyl end group is changed from a ketone $\left(\mathrm{pCK}^{-}\right)$ to a thioester $\left(\mathrm{pCT}^{-}\right)$, an ester $\left(\mathrm{pCE}^{-}\right)$, an amide $\left(\mathrm{pCM}^{-}\right)$and a carboxylate $\left(\mathrm{pCA}^{2-}\right)$. This result is emphasized in Fig. 5, which shows decays recorded close to the maximum of the steady-state fluorescence spectra, at wavelengths where the effect of solvation is found to be minimal. In addition, the figure emphasizes the excellent agreement with decays extracted from time-resolved transient absorption measurements in the gain band., ${ }^{4,10,12,20}$

This demonstrates that the electron-acceptor character of the carbonyl end group has a direct influence on the excited-state lifetime. This is illustrated in Fig. 6, where the logarithm of the decay constant $\left(k_{\mathrm{S} 1}=1 / \tau_{2}\right.$, Table 1$)$ is plotted as a function of the Hammett parameter of $\mathrm{X}^{33}$ One notes that $\mathrm{pCK}^{-}$has a decay constant slightly larger than that of $\mathrm{pCT}^{-}$, although $\sigma_{\mathrm{p}}$ is smaller for $\mathrm{CH}_{3}$ than for $\mathrm{S}-\mathrm{C}_{6} \mathrm{H}_{5}$. The data are somewhat scattered but the general trend is an increase of $\ln \left(k_{\mathrm{S} 1}\right)$ with $\sigma_{\mathrm{p}}$, which we have illustrated by a simple linear relationship. As already stressed in previous studies, ${ }^{18-20}$ the coupling between the locally excited-state and a charge-transfer state appears as the driving force for the excited-state population decay channel in these compounds. The photoinduced reaction is thought to be promoted by the optically induced charge shift from the phenolate group to the ethylenic
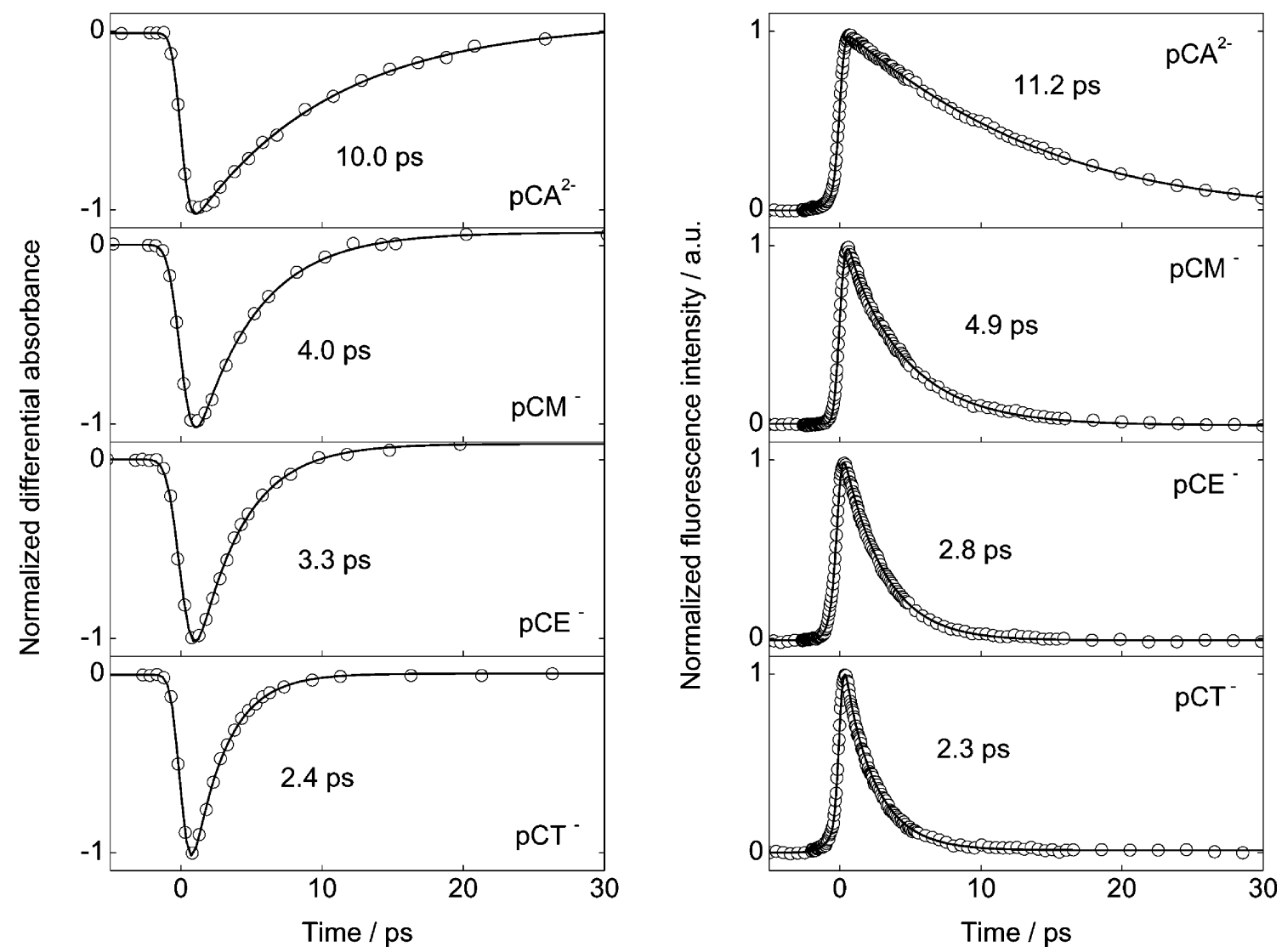

Fig. 5 Comparison of the decays of the stimulated emission (left) and of the fluorescence (right) of the deprotonated forms of trans-p-coumaric acid $\left(\mathrm{pCA}^{2-}\right)$, its amide $\left(\mathrm{pCM}^{-}\right)$, ester-methyl $\left(\mathrm{pCE}^{-}\right)$and thioester-phenyl $\left(\mathrm{pCT}^{-}\right)$derivatives in basic aqueous solutions, in a wavelength-range where the component due to the solvation induced shift is negligible. 


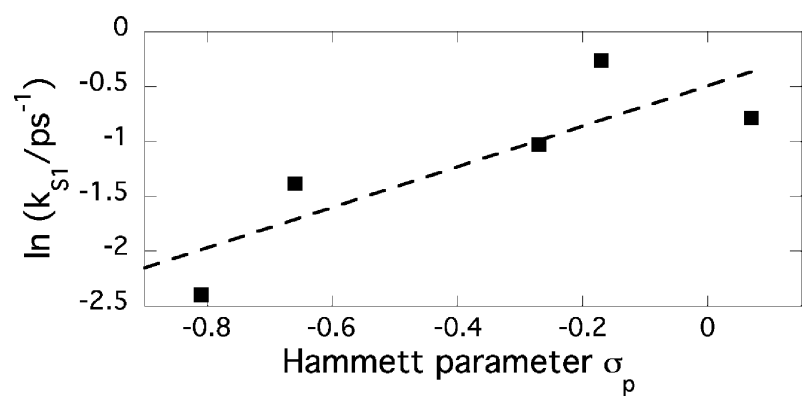

Fig. 6 Logarithm of the excited-state decay constant $\left(k_{\mathrm{S} 1}=1 / \tau_{2}\right.$, Table 1) as a function of the Hammett $\sigma_{\mathrm{p}}$ parameter of the substituent of the carbonyl-end group measured for all analogues shown in Scheme 1.

bond, and to involve further electron shift towards the carbonyl end group and a charge localization. The equilibrium geometry of the charge-transfer state is supposed to be different from that of the initially excited state.

\section{Photoinduced relaxation coordinates}

Subpicosecond transient absorption experiments demonstrated that, if the electron-acceptor character of the end group is weak $\left(\mathrm{pCA}^{2-}\right.$ and $\mathrm{pCM}^{-}$), trans-cis photoisomerisation occurs without any detectable intermediate. ${ }^{4,9,12,18}$ If it is strong, the excitedstate relaxation pathway involves a spectroscopically detectable intermediate and likely leads to little $\left(\mathrm{pCE}^{-}\right)^{20}$ or no cis-isomer formation $\left(\mathrm{pCT}^{-}\right) .{ }^{18}$ No transient absorption data are available at present for $\mathrm{pCK}^{-}$which nevertheless does not undergo net transcis photoisomerisation (Fig. 2).

It was proposed that depending on the electron-acceptor character of the end group, the relaxation process involves different molecular coordinates and pathways, which can partially lead to the cis isomer or totally lead back to the trans isomer. ${ }^{18,20}$ The fact that the sensitivity of the excited-state decay rate to the solvent viscosity depends on the electron donor-acceptor strength ${ }^{18-20}$ was used as a support to this proposal. By using the phenomenological power law $k=C \eta^{-a}$, where the parameter $a(0<a \leq 1)$ gauges the strength of the solvent damping, $C$ is a constant proportional to the activation barrier term and $\eta$ the solvent viscosity, $\alpha$ was indeed found to be 2 to 3 times larger for $\mathrm{pCT}^{-}$than for $\mathrm{pCA}^{2-} .^{18}$ From Grote and Hynes' theory, ${ }^{34}$ it is known that a solvent exerts a time-dependent friction that controls the barrier crossing rate of an activated process. The low-frequency friction exerted by a viscous solvent is expected to affect only low-frequency barriers, which are generally low-energy barriers. The change in the viscosity effect observed for the present analogues is thus expected to reflect a change in the curvature of the barrier, that is, in the reaction freeenergy profile. Such a change may as well arise from a modification of the coordinates involved in the excited-state decay channel. The values of $a$ measured by transient absorption in a series of linear alcohols and by fluorescence up-conversion in waterglycerol mixtures are given in Table 2 for all analogues.

Table 2 shows that, except for $\mathrm{pCK}^{-}, \alpha$ tends to increase with the electron-acceptor character of the carbonyl group. In addition, the excited-state decay rate of the neutral forms pCKH and $\mathrm{pCEH}$, where the electron donor character of the donor site is strongly decreased (the phenolate group is protonated) were found to be barely sensitive to viscosity. ${ }^{19}$
Table 2 Parameter $a$ of the phenomenological power law $k \propto \eta^{-a}$ gauging the solvent viscosity $(\eta)$ effect on the excited-state decay-rate $(k)$ of basic solutions of all PYP chromophore analogues shown in Scheme 1. Regression coefficients are given within parentheses

\begin{tabular}{|c|c|c|}
\hline & $\begin{array}{l}\text { Parameter } \alpha \text { measured by } \\
\text { transient absorption in a } \\
\text { series of linear alcohols }\end{array}$ & $\begin{array}{l}\text { Parameter } a \text { measured by } \\
\text { fluorescence up-conversion in } \\
\text { water-glycerol mixtures }\end{array}$ \\
\hline $\mathrm{pCA}^{2-}$ & $0.38(0.89)^{18}$ & \\
\hline $\mathrm{pCM}^{-}$ & $0.56(0.82)$ & \\
\hline $\mathrm{pCE}^{-}$ & & $0.64(0.99)^{19}$ \\
\hline $\mathrm{pCT}^{-}$ & $0.75(0.85)^{18}$ & \\
\hline $\mathrm{pCK}^{-}$ & & $0.54(0.99)$ \\
\hline
\end{tabular}

The light-induced molecular response of these compounds is very likely to change from different types of concerted motions to a one-bond flip motion (torsion around the ethylenic bond) depending on the extent of the photoinduced charge shift. This is related to the molecular flexibility in the excited state because, for analogues with a strong electron-acceptor end group, a complete photoinduced charge shift until the carbonyl oxygen is expected to occur and to induce a complete reversal of the single and double bond pattern, the central ethylenic bond becoming a single bond. With weak electron-accepting end groups one expects either a charge shift of a lesser extent and thus a less rigid structure. ${ }^{20}$

For protonated ester and ketone analogues, ${ }^{19}$ which have the weakest electron donor-acceptor structure and the weakest viscosity dependence, motions like hula-twist ${ }^{35}$ or bicycle-pedal ${ }^{36}$ have been proposed. It is interesting to note that photoisomerisation of the neutral form of pCT has been observed in crystalline phase in spite of the tight crystal packing ${ }^{37}$ also suggesting a volumeconserving photoisomerisation coordinate. For the anionic $\mathrm{pCA}^{2-}$ analogue, which has a weak electron-acceptor carbonyl end group and experiences a small but non-negligible viscosity effect, a mechanism involving the concerted torsion of the ethylenic bond and the carbonyl end group has been invoked for reaching the perp state that leads to the cis isomer. ${ }^{18,20}$ While $\mathrm{pCM}^{-}$can be classified with $\mathrm{pCA}^{2-}, \mathrm{pCE}^{-}$and $\mathrm{pCT}^{-}$which bear a better electronaccepting carbonyl end group and exhibit a larger viscosity effect are thought to involve a single one-bond flip.

The present study brings further support to the idea that in solution the electron donor-acceptor character of the chromophore structure controls the excited-state relaxation channel starting from the Franck-Condon state. This differs from PYP, for which a primary light-induced response controlled by the protein environment, ${ }^{1-6,38-46}$ in particular by the structure and constraints of the protein nanospace, ${ }^{3,38-43,46}$ has been proposed.

\section{Conclusion}

The nature of the carbonyl end group substituent of analogues of the photoactive yellow protein (PYP) chromophore, a thioester derivative of deprotonated trans- $p$-coumaric acid, has a direct influence on the excited-state population decay time. If the substituent is changed from $\mathrm{O}^{-}$to $\mathrm{NH}_{2}, \mathrm{O}-\mathrm{CH}_{3}, \mathrm{~S}-\mathrm{C}_{6} \mathrm{H}_{5}$ and $\mathrm{CH}_{3}$, the fluorescence lifetime decreases from $c a .10$ ps down to $c a$. 1 ps. The values are in excellent agreement with those previously extracted from transient absorption measurements. The observed subpicosecond redshift of the reconstructed fluorescence spectra is attributed to solvation dynamics around the emissive 
state of charge-transfer character. The logarithm of the excitedstate decay-rate increases with the Hammett parameter of the carbonyl substituent, demonstrating the direct influence of the electron donor-acceptor character of the chromophore structure on the excited-state decay channel. Steady-state photolysis is not observed for the analogues having the strongest electron donoracceptor structure. The relaxation coordinates are proposed to change from concerted motions to a one-bond flip motion (torsion around the ethylenic bond) depending on the extent of the photoinduced charge shift on the chromophore skeleton. The results emphasize the discrepancy between the light-induced primary response of the free thioester model analogue of the PYP chromophore in solution and that known for PYP, which was reported to be controlled by the structure and constraints of the protein nanospace. ${ }^{3,38-43,46}$

\section{Acknowledgements}

The authors thank Jean-Bernard Baudin and Ludovic Jullien for providing $\mathrm{pCMH}, \mathrm{pCEH}$ and $\mathrm{pCTH}$ which were synthesized in their group. MMM thanks Albert M. Brouwer for helpful suggestions. This collaborative work was done within the framework of a Blaise Pascal Chair AHZ was awarded at the Department of Chemistry of the Ecole Normale Superieure (ENS) in Paris. Financial support from the ENS Foundation is acknowledged. $\mathrm{AE}$ is grateful to Caltech for a Graduate Fellowship during her stay in Pasadena.

\section{References}

1 K. J. Hellingwerf, J. Hendriks and T. Gensch, Photoactive yellow protein, a new type of photoreceptor protein: Will this "yellow lab" bring us where we want to go?, J. Phys. Chem. A, 2003, 107, 10821094.

2 M. A. Cusanovich and T. E. Meyer, Photoactive yellow protein: a prototypic PAS domain sensory protein and development of a common signaling mechanism, Biochemistry, 2003, 42, 4759-4770.

3 N. Mataga, H. Chosrowjan and S. Taniguchi, Investigations into the dynamics and mechanisms of ultrafast photoinduced reactions taking place in photoresponsive protein nanospaces (PNS), J. Photochem. Photobiol., C, 2004, 5, 155-168.

4 P. Changenet-Barret, A. Espagne, P. Plaza, K. J. Hellingwerf and M. M. Martin, Investigations of the primary events in a bacterial photoreceptor for photomotility: photoactive yellow protein (PYP), New J. Chem., 2005, 4, 527-534.

5 D. S. Larsen and R. van Grondelle, Initial photoinduced dynamics of the photoactive yellow protein, ChemPhysChem, 2005, 6, 828-837.

6 L. J. G. W. van Wilderen, M. A. van der Horst, I. H. M. van Stokkum, K. J. Hellingwerf, R. van Grondelle and M. L. Groot, Ultrafast infrared spectroscopy reveals a key step for successful entry into the photocycle for photoactive yellow protein, Proc. Natl. Acad. Sci. USA, 2006, 103, $15050-15055$.

7 W. W. Sprenger, W. D. Hoff, J. P. Armitage and K. J. Hellingwerf, The eubacterium Ectothiorhodospira halophila is negatively phototactic, with a wavelength dependence that fits the absorption spectrum of the photoactive yellow protein, J. Bacteriol., 1993, 175, 30963104.

8 D.-P. Häder and M. Lebert, Photomovement, in Comprehensive series in photosciences, Elsevier, Amsterdam, 2001.

9 P. Changenet-Barret, P. Plaza and M. M. Martin, Primary events in the photoactive yellow protein chromophore in solution, Chem. Phys. Lett., 2001, 336, 439-444.

10 P. Changenet-Barret, A. Espagne, N. Katsonis, S. Charier, J.-B. Baudin, L. Jullien, P. Plaza and M. M. Martin, Excited-state relaxation dynamics of a PYP chromophore model in solution: Influence of the thioester group, Chem. Phys. Lett., 2002, 365, 285-291.
11 D. S. Larsen, M. Vengris, I. H. M. Van Stokkum, M. A. van der Horst, R. A. Cordfunke, K. J. Hellingwerf and R. van Grondelle, Initial photoinduced dynamics of the photoactive yellow protein chromophore in solution, Chem. Phys. Lett., 2003, 369, 563-569.

12 P. Changenet-Barret, A. Espagne, S. Charier, J.-B. Baudin, L. Jullien, P. Plaza, K. J. Hellingwerf and M. M. Martin, Early molecular events in the photoactive yellow protein : Role of the chromophore photophysics, Photochem. Photobiol. Sci., 2004, 3, 823-829.

13 D. S. Larsen, M. Vengris, I. H. M. van Stokkum, M. A. van der Horst, F. L. de Weerd, K. J. Hellingwerf and R. van Grondelle, Photoisomerization and photoionization of the photoactive yellow protein chromophore in solution, Biophys. J., 2004, 86, 2538-2550.

14 M. Vengris, M. A. van der Horst, G. Zgrablic, I. H. M. van Stokkum, S. Haacke, M. Chergui, K. J. Hellingwerf, R. van Grondelle and D. S. Larsen, Contrasting the excited-state dynamics of the photoactive yellow protein chromophore: Protein vs. solvent environments, Biophys. J., 2004, 87, 1848-1857.

15 M. Vengris, D. S. Larsen, M. A. van der Horst, O. F. A. Larsen, K. J. Hellingwerf and R. van Grondelle, Ultrafast dynamics of isolated model photoactive yellow protein chromophores: "Chemical perturbation theory" in the laboratory, J. Phys. Chem. B, 2005, 109, 4197-4208.

16 H. El-Gezawy, W. Rettig, A. Danel and G. Jonusauskas, Probing the photochemical mechanism in photoactive yellow protein, J. Phys. Chem. B, 2005, 109, 18699-18705.

17 A. Usman, O. F. Mohammed, K. Heyne, J. Dreyer and E. T. J. Nibbering, Excited state dynamics of a PYP chromophore model system explored with ultrafast infrared spectroscopy, Chem. Phys. Lett., 2005, 401, 157-163.

18 A. Espagne, P. Changenet-Barret, P. Plaza and M. M. Martin, Solvent effect on the excited-state dynamics of analogues of the photoactive yellow protein chromophore, J. Phys. Chem. A, 2006, 110, 3393-3404.

19 A. Espagne, D. H. Paik, P. Changenet-Barret, M. M. Martin and A. H. Zewail, Ultrafast photoisomerization of photoactive yellow protein chromophore analogues in solution: Influence of the protonation state, ChemPhysChem, 2006, 7, 1717-1726.

20 A. Espagne, P. Changenet-Barret, P. Plaza, J.-B. Baudin and M. M. Martin, Photoinduced charge shift as the driving force for the excited-state relaxation of analogues of the photoactive yellow protein chromophore in solution, J. Photochem. Photobiol., A, 2007, 185, 245252.

21 I. B. Nielsen, S. Boye-Peronne, M. O. A. El Ghazaly, M. B. Kristensen, S. B. Nielsen and L. H. Andersen, Absorption spectra of photoactive yellow protein chromophores in vacuum, Biophys. J., 2005, 89, 25972604.

22 I.-R. Lee, W. Lee and A. H. Zewail, Primary steps of the photoactive yellow protein: Isolated chromophore dynamics and protein directed function, Proc. Natl. Acad. Sci. USA, 2006, 103, 258-262.

23 T. Fiebig, C. Z. Wan and A. H. Zewail, Femtosecond charge transfer dynamics of a modified DNA base: 2-aminopurine in complexes with nucleotides, ChemPhysChem, 2002, 3, 781-788.

24 M. Maroncelli and G. R. Fleming, Picosecond solvation dynamics of coumarin 153: The importance of molecular aspects of solvation, J. Chem. Phys., 1987, 86, 6221-6239.

25 B. Borucki, H. Otto, T. E. Meyer, M. A. Cusanovich and M. P. Heyn, Sensitive circular dichroism marker for the chromophore environment of photoactive yellow protein: assignment of the 307 and $318 \mathrm{~nm}$ bands to the np* transition of the carbonyl, J. Phys. Chem. B, 2005, 109, 629633.

26 G. Aulin-Erdtman and R. Sandèn, Spectrographic contributions to lignin Chemistry, Acta Chem. Scand., 1968, 22, 1187-1209.

27 Y. Maeda, T. Okada and N. Mataga, Photoinduced trans $\rightarrow$ cis isomerization and intramolecular-charge-transfer interaction. Photochemistry and picosecond laser spectroscopy of 4-substituted $\beta$-(1pyrenyl)styrenes, J. Phys. Chem., 1984, 88, 2714-2718.

28 F. D. Lewis, J. E. Elbert, A. L. Upthagrove and P. D. Hale, Lewis-acid catalysis of photochemical reactions. 9. Structure and photoisomerization of $(E)$ - and $(Z)$-cinnamamides and their Lewis acid complexes, J. Org. Chem., 1991, 56, 553-561.

29 A. M. Brouwer, S. M. Fazio, N. Haraszkiewicz, D. A. Leigh and C. M. Lennon (neé Keaveney), Coumaric amide rotaxanes: effects of hydrogen bonding and mechanical interlocking on the photochemistry and photophysics, Photochem. Photobiol. Sci., 2007, 4, 480-486.

30 J. Berna, A. M. Brouwer, S. M. Fazio, N. Haraszkiewicz, D. A. Leigh and C. M. Lennon, A rotaxane mimic of the photoactive 
yellow protein chromophore environment: effects of hydrogen bonding and mechanical interlocking on a coumaric amide derivative, Chem. Commun., 2007, DOI: 10.1039/b618781a.

31 R. Jimenez, G. R. Fleming, P. V. Kumar and M. Maroncelli, Femtosecond solvation dynamics of water, Nature, 1994, 369, 471-473.

32 L. L. Premvardhan, F. Buda, M. A. van der Horst, D. C. Lührs, K. J. Hellingwerf and R. van Grondelle, Impact of photon absorption on the electronic properties of $\mathrm{p}$-coumaric acid derivatives of the photoactive yellow protein chromophore, J. Phys. Chem. B, 2004, 108, 5138-5148.

33 C. Hansch, A. Leo and R. W. Taft, A survey of Hammett substituent constants and resonance and field parameters, Chem. Rev., 1991, 91, $165-195$.

34 R. F. Grote and J. T. Hynes, The stable states picture of chemical reactions. II. Rate, constants for condensed and gas phase reaction models, J. Chem. Phys., 1980, 73, 2715-2732.

35 R. S. H. Liu and A. E. Asato, The primary process of vision and the structure of bathorhodopsin: A mechanism for photoisomerization of polyenes, Proc. Natl. Acad. Sci. USA, 1985, 82, 259-263.

36 A. Warshel, Bicycle-pedal model for the first step in the vision process, Nature, 1976, 260, 679-683.

37 A. Usman, H. Masuhara and T. Asahi, Trans-cis photoisomerization of a photoactive yellow protein model chromophore in crystalline phase, J. Phys. Chem. B, 2006, 110, 20085-20088.

38 H. Chosrowjan, N. Mataga, N. Nakashima, Y. Imamoto and F. Tokunaga, Femtosecond-picosecond fluorescence studies on excited state dynamics of photoactive yellow protein from Ectothiorhodospira Halophila, Chem. Phys. Lett., 1997, 270, 267-272.

39 H. Chosrowjan, N. Mataga, Y. Shibata, Y. Imamoto and F. Tokunaga, Environmental effects on the femtosecond-picosecond fluorescence dynamics of photoactive yellow Protein: Chromophores in aqueous solutions and in protein nanospaces modified by site-directed mutagenesis, J. Phys. Chem. B, 1998, 102, 7695-7698.
40 H. Chosrowjan, S. Taniguchi, N. Mataga, M. Unno, S. Yamauchi, N. Hamada, M. Kumauchi and F. Tokunaga, Low-frequency vibrations and their role in ultrafast photoisomerization reaction dynamics of photoactive yellow protein, J. Phys. Chem. B, 2004, 108, 26862698.

41 N. Mataga, H. Chosrowjan, Y. Shibata, Y. Imamoto and F. Tokunaga, Effects of modification of protein nanospace structure and change of temperature on the femtosecond to picosecond fluorescence dynamics of photoactive yellow protein, J. Phys. Chem. B, 2000, 104, 51915199.

42 N. Mataga, H. Chosrowjan, Y. Shibata, Y. Imamoto, M. Kataoka and F. Tokunaga, Ultrafast photoinduced reaction dynamics of photoactive yellow protein (PYP): Observation of coherent oscillations in the femtosecond fluorescence decay dynamics, Chem. Phys. Lett., 2002, 352, 220-225.

43 N. Mataga, H. Chosrowjan, S. Taniguchi, N. Hamada, F. Tokunaga, Y. Imamoto and M. Kataoka, Ultrafast photoreactions in protein nanospaces as revealed by fs fluorescence dynamics measurements on photoactive yellow protein and related systems, Phys. Chem. Chem. Phys., 2003, 5, 2454-2460.

44 S. Devanathan, S. Lin, M. A. Cusanovich, N. Woodbury and G. Tollin, Early intermediates in the photocycle of the Glu46Gln mutant of photoactive yellow protein: femtosecond spectroscopy, Biophys. J., 2000, 79, 2132-2137.

45 S. Devanathan, S. Lin, M. A. Cusanovich, N. Woodbury and G. Tollin, Early photocycle kinetic behavior of the E46A and Y42F mutants of photoactive yellow protein: Femtosecond spectroscopy, Biophys. J., 2001, 81, 2314-2319.

46 P. Changenet-Barret, P. Plaza, M. M. Martin, H. Chosrowjan, S. Taniguchi, N. Mataga, Y. Imamoto and M. Kataoka, Role of arginine 52 on the primary photoinduced events in the PYP photocycle, Chem. Phys. Lett., 2007, 434, 220-225. 